\title{
Bilateral breast adenocarcinomas with EML4- $A L K$ fusion in a patient with multiple metastases successfully treated with crizotinib: is lung the primary site?
}

\author{
This article was published in the following Dove Press journal: \\ OncoTargets and Therapy \\ 16 June 2016 \\ Number of times this article has been viewed
}

\author{
Chao Liu ${ }^{1,2}$ \\ Lijuan Ding ${ }^{2}$ \\ Bing Sun ${ }^{2}$ \\ Shikai $\mathrm{Wu}^{1,2}$ \\ 'Department of Radiation Oncology, \\ 307 Hospital of People's Liberation \\ Army, 307 Clinical College, Anhui \\ Medical University, ${ }^{2}$ Department \\ of Radiation Oncology, Affiliated \\ Hospital of Academy of Military \\ Medical Sciences, Beijing, People's \\ Republic of China
}

\begin{abstract}
Breast metastases from non-mammary cancers are rare, especially when they appear synchronously. Clinically, it is vitally important to accurately diagnose these patients, as this will directly influence their treatment and survival. We present a very rare and complex case of bilateral breast adenocarcinomas with an EML4-ALK fusion, which was diagnosed as bilateral breast metastases of non-small-cell lung cancer by immunohistochemistry and comprehensive genomic investigation. The patient was successfully treated with an $A L K$ inhibitor (crizotinib); symptoms improved quickly after initiation of crizotinib therapy, and a partial response was observed after 3 months. The experience of diagnosis and treatment of this case indicates the importance and necessity of genomic investigations in such patients, and suggests that we need to consider the rare possibility of this kind of metastasis in order to provide optimal treatment.
\end{abstract}

Keywords: ALK inhibitor, metastatic adenocarcinoma, gene expression profiling

\section{Introduction}

Extramammary cancers rarely metastasize to mammary glands, and such metastases account for approximately $0.23 \%-1.2 \%$ of breast tumors. ${ }^{1-3}$ It is important to distinguish metastatic disease of the breast from primary breast cancer. Histopathology and imaging are vital techniques used for diagnosis. However, in some rare cases, these two methods are unable to determine the primary tumor site because of their lack of specificity. Recently, genomic investigation has emerged as a useful tool to aid accurate diagnosis. ${ }^{4}$

The $E M L 4-A L K$ fusion gene generally expresses in adenocarcinomas. Therapies targeting the $A L K$ gene, such as crizotinib or ceritinib, induce remarkable responses in patients harboring $A L K$ rearrangements. ${ }^{5,6}$ Here, we report an extremely rare case of $A L K$-positive non-small-cell lung cancer (NSCLC) with bilateral breast metastases, which was successfully diagnosed by immunohistochemistry and comprehensive genomic profiling, and treated with a tyrosine kinase inhibitor (TKI).

\section{Case report}

Correspondence: Shikai Wu Department of Radiation Oncology, 307 Hospital of People's Liberation Army, No 8 East Road, Fengtai District, Beijing I0007I, People's Republic of China Tel/fax +86 106694 7196

Email skywu4923@sina.com
A 37-year-old nonsmoking female was admitted to a local hospital in August 2014 with a 1-week history of mild cough, sputum, and a palpable mass in her left breast. She was healthy and had no family history of tumor. She was treated for pneumonia at the local hospital, and her cough improved. However, 1 month later, her symptoms became severe. A computed tomography scan of the chest showed bilateral lung masses 

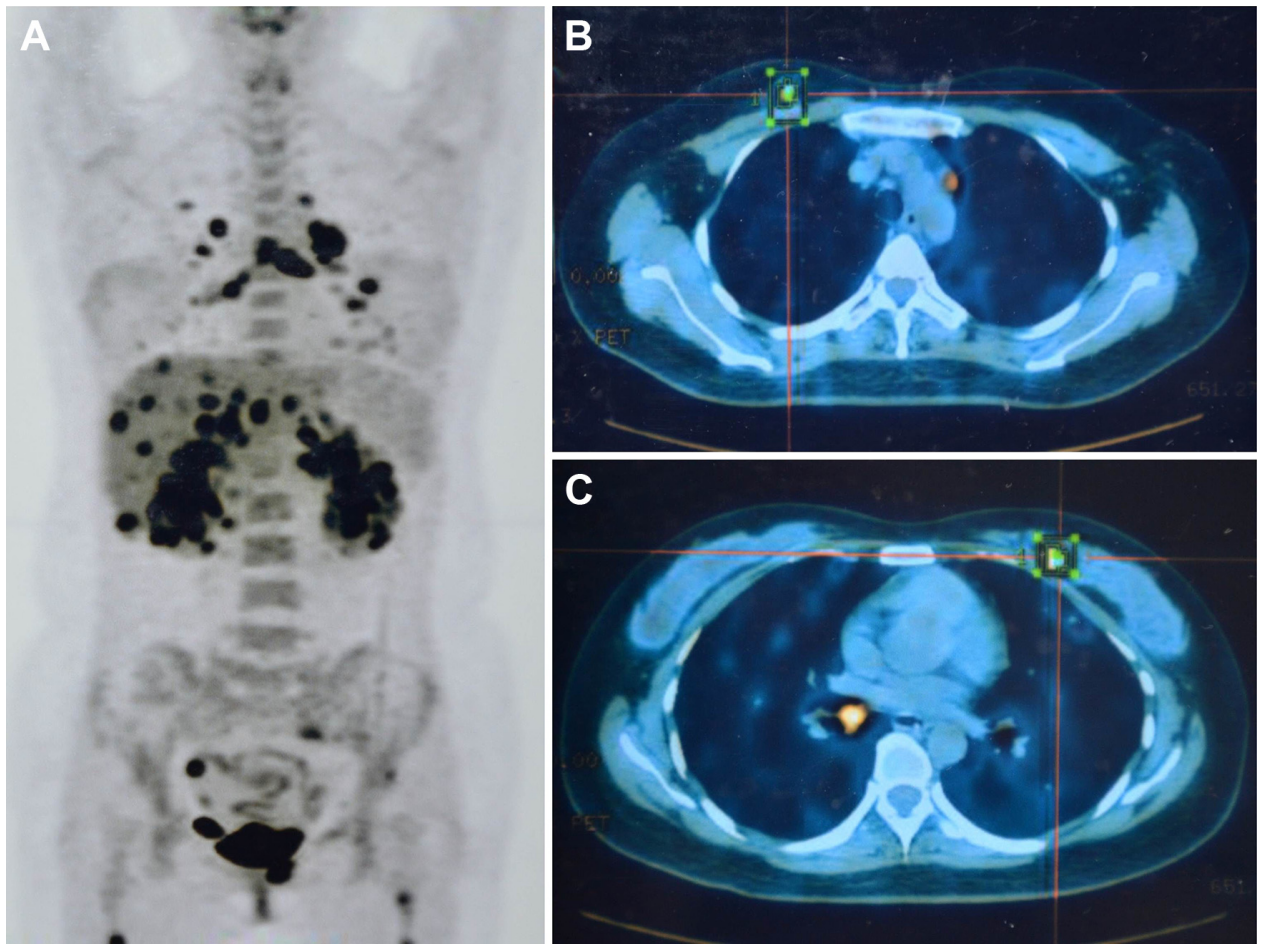

Figure I Images of PET-CT for the patient.

Notes: (A) Whole-body FDG fusion PET-CT showed numerous masses in the body. (B and C) PET-CT showed bilateral breast masses. Abbreviations: FDG, fluorodeoxyglucose; PET-CT, positron emission tomography-computed tomography.

and enlargement of multiple lymph nodes in the mediastinum. Positron emission tomography-computed tomography revealed enlarged lymph nodes in the pulmonary hilum and mediastinum and multiple masses in the brain, bilateral lungs, breasts, adrenal glands, liver, body of the T6 vertebra, and spinal marrow of the C6 vertebra (Figure 1).

The patient was referred to our hospital in October 2014. Ultrasound-guided needle biopsy of the bilateral breast lesions was performed, and a poorly differentiated adenocarcinoma was diagnosed by pathology (Figure 2A). Immunohistochemistry results were negative for ER, PR, Her-2, and Napsin A (Figure 2B), and positive for TTF-1 (Figure 2C), CA-153, and Ki-67 (index 20\%). Based on these findings, the patient underwent two cycles of treatment with taxotere and cisplatin, and whole-brain radiotherapy. Tumor response based on RECIST $1.1^{7}$ was a stable disease. Meanwhile, bilateral breast masses were assayed for genomic alterations using FoundationOne (Foundation Medicine, Inc., Cambridge, MA, USA). Three hundred and fifteen genes and introns of 28 genes involved in rearrangements were examined, and the only genomic alteration of clinical significance was found in variant 1 of EML4- $A L K$ fusion gene. Immunohistochemical examination for $A L K$ was also strongly positive (Figure 2D).

The patient received oral treatment with crizotinib (250 mg, twice a day) from January 2015, and her cough was dramatically relieved. Surprisingly, partial response was observed after 3 months of treatment with crizotinib (Figure 3). Fatigue (grade 1), decreased appetite (grade 1), neutropenia (grade 3), and bradycardia were identified in the patient during crizotinib treatment. In October 2015, a number of small masses appeared in the brain of the patient without symptoms, while the partial response of extracranial masses continued. Two months later, the patient deteriorated with memory deficit, hyponoia, and convulsions. In January 2016, treatment with a new ALK inhibitor (AP26113) was initiated; however, the patient went into a coma several days after the initiation of AP26113 and died after 3 weeks.

This study was approved by the Ethical Committee of Affiliated Hospital of Academy of Military Medical Sciences. The patient signed written informed consent.

\section{Discussion}

The diagnosis and treatment of this rare case are notable. Primary lung cancer generally spreads to the brain, bones, liver, kidneys, and adrenal glands. Nevertheless, breast metastasis from a lung tumor is extremely rare, especially appearing synchronously. To the best of our knowledge, only eleven cases of synchronously appearing NSCLCs and breast metastases have been reported previously. ${ }^{8}$ As useful markers, Napsin A and TTF-1 are positive in $86.7 \%$ 

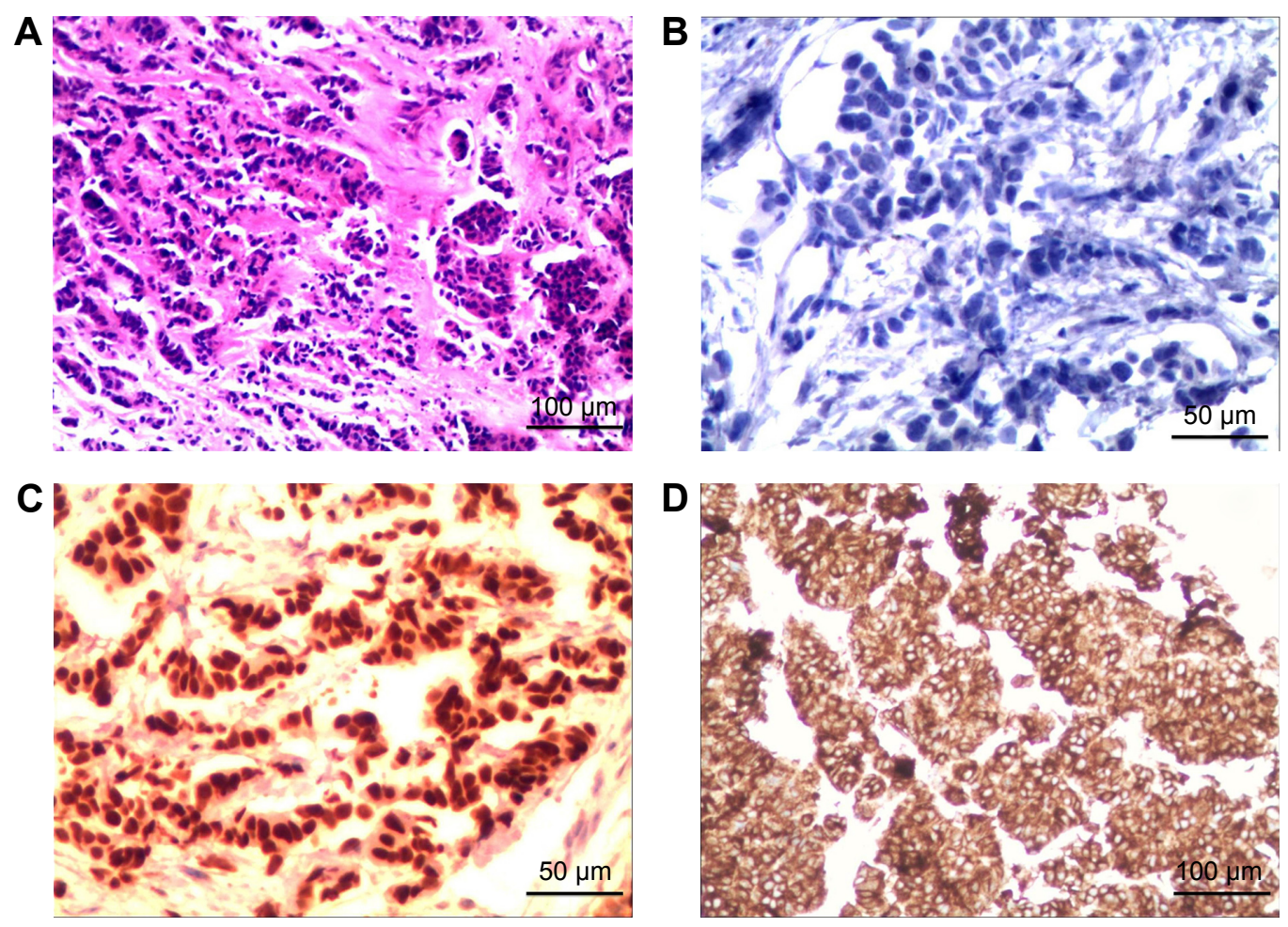

Figure 2 Images of hematoxylin-eosin staining and immunohistochemistry of breast masses.

Notes: (A) Hematoxylin-eosin staining of the breast masses showed a poorly differentiated adenocarcinoma. (B) Immunohistochemistry of tumor cells was negative for Napsin A. Immunostaining revealed positivity for tumor for (C) TTF-I and (D) ALK. A and D (magnification, I00×), B and C (magnification, 200×).

and $83.3 \%$ of lung adenocarcinomas, respectively. ${ }^{9} \mathrm{We}$ also note that TTF-1 positivity is rare but does occur in primary breast cancer, being reported in $2.4 \%$ of cases. ${ }^{10}$ The case reported here was Napsin A-, ER-, PR-, and Her-2 negative but TTF-1 positive. Based on this evidence and the radiologic images demonstrating many small masses in both the lungs, we surmised that the primary site was the lung. To confirm this, tests for genomic mutations were performed, and the positive result for $A L K$ strongly supported the hypothesis that the primary tumor was NSCLC. Nevertheless, the extremely minor possibility of a primary breast tumor could not be ruled out. Although the EML4-ALK fusion gene is characteristic of NSCLC, it has also been identified in $2.4 \%$ of breast cancer patients (five of 209), including three basal-like cases, ${ }^{11}$ and TTF-1 expression has also been observed in breast tumor. ${ }^{10}$ Thus, two more markers for breast cancer, GATA3
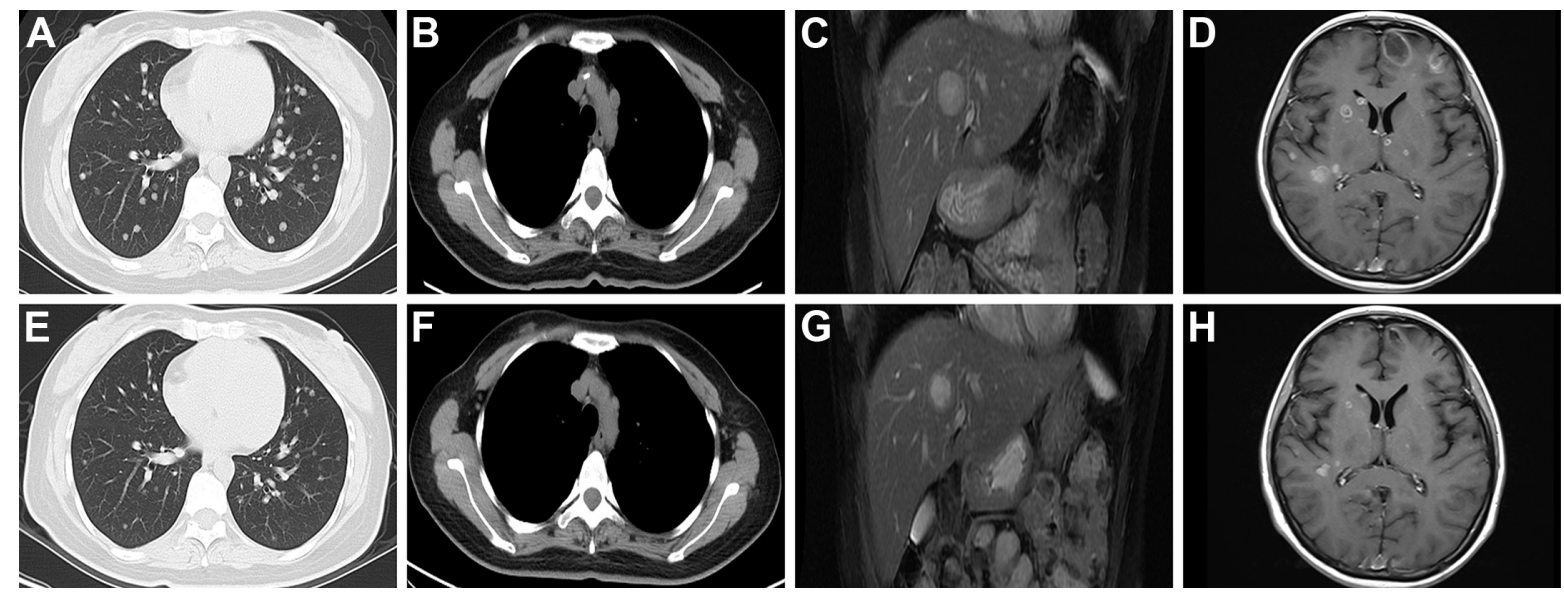

Figure $3 \mathrm{CT}$ scan and MRI before and after 3 months treatment with crizotinib.

Notes: (A-D) CT scan and MRI showed masses in the lungs, lymph nodes in the mediastinum, liver, and brain before treatment with crizotinib. (E-H) CT and MRI showed a significant response after 3 months treatment with crizotinib.

Abbreviations: $\mathrm{CT}$, computed tomography; MRI, magnetic resonance imaging. 
and GCDFP-15, were examined. Negative results for these markers confirmed a definite diagnosis of NSCLC.

Regarding treatment, crizotinib is approved for the treatment of local-advanced or metastatic $A L K$-positive NSCLC patients and exhibits remarkable efficacy. ${ }^{12}$ An open-label, randomized Phase III clinical trial was conducted, comparing the efficacy and safety of crizotinib with pemetrexed-based chemotherapy in patients with $A L K$-positive nonsquamous NSCLC. The results for the crizotinib group were considerably superior to those for the pemetrexed-based chemotherapy group, in terms of objective response rate, 1-year survival, quality of life, and symptoms reduction. ${ }^{5}$ Furthermore, antitumor activity of crizotinib has been demonstrated in several other $A L K$-positive tumors, including lymphomas, inflammatory myofibroblastic tumors, and neuroblastoma. ${ }^{13-15}$ Patients receiving crizotinib do experience adverse effects, including vision disorders, diarrhea, nausea, neutropenia, vomiting, constipation, edema, elevated transaminases, fatigue, and decreased appetite. ${ }^{5,16}$ Our patient experienced grade 1 fatigue, decreased appetite, grade 3 neutropenia, and bradycardia.

The development of new intracranial lesions in patients resistant to crizotinib is common. In the case presented here, the time to intracranial progression was $\sim 13$ months, which is similar to that reported by Costa et al. ${ }^{17}$ The understanding of mechanism of acquired resistance to crizotinib and knowledge of suitable subsequent treatments for patients with $A L K$ rearrangement are important. Activation of bypass signaling pathways, such as the EGFR activation, is a probable mechanism of resistance; however, more evidence from clinical trials is required. If this mechanism is confirmed, the use of $A L K$ plus EGFR TKIs may be beneficial to patients resistant to crizotinib. ${ }^{18}$ Other possible mechanisms include point mutations affecting the fusion protein, copy number gain of $A L K$, and unidentified mechanisms. ${ }^{19}$

In addition to crizotinib, new $A L K$ inhibitors, such as ceritinib, alectinib, and AP26113, could be used to treat ALK-positive patients who show resistance to crizotinib. It has been reported that new $A L K$ inhibitors remain highly active in patients who have previously received crizotinib, including those with brain metastases. ${ }^{6,19,20}$ In addition, traditional treatments may be a reasonable option for crizotinibresistant patients. However, the case reported here went into a coma after the initiation of treatment with AP26113, which may have been a consequence of the severe progression of intracranial masses.

In conclusion, comprehensive assessment of genomic alterations is important for the diagnosis and treatment of this kind of rare cancer, and should be performed initially. In addition, initial treatment with a TKI provides considerable benefits to patients with gene mutations by prolonging the progression-free survival, relieving symptoms, and improving the quality of life.

\section{Disclosure}

The authors report no conflicts of interest in this work.

\section{References}

1. Lee SK, Kim WW, Kim SH, et al. Characteristics of metastasis in the breast from extramammary malignancies. J Surg Oncol. 2010;101(2): 137-140.

2. Alvarado Cabrero I, Carrera Alvarez M, Perez Montiel D, et al. Metastases to the breast. Eur J Surg Oncol. 2003;29(10):854-855.

3. Hajdu SI, Urban JA. Cancers metastatic to the breast. Cancer. 1972;29(6): 1691-1696

4. Gatalica Z, Millis SZ, Vranic S, et al. Comprehensive tumor profiling identifies numerous biomarkers of drug response in cancers of unknown primary site: analysis of 1806 cases. Oncotarget. 2014;5(23): 12440-12447.

5. Solomon BJ, Mok T, Kim DW, et al. First-line crizotinib versus chemotherapy in ALK-positive lung cancer. N Engl J Med. 2014;371(23): 2167-2177.

6. Shaw AT, Kim DW, Mehra R, et al. Ceritinib in ALK-rearranged nonsmall-cell lung cancer. N Engl J Med. 2014;370(13):1189-1197.

7. Eisenhauer EA, Therasse P, Bogaerts J, et al. New response evaluation criteria in solid tumours: revised RECIST guideline (version 1.1). Eur J Cancer. 2009;45(2):228-247.

8. Mirrielees JA, Kapur JH, Szalkucki LM, et al. Metastasis of primary lung carcinoma to the breast: a systematic review of the literature. J Surg Res. 2014;188(2):419-431.

9. El-Maqsoud NM, Tawfiek ER, Abdelmeged A, et al. The diagnostic utility of the triple markers Napsin A, TTF-1, and PAX8 in differentiating between primary and metastatic lung carcinomas. Tumour Biol. 2016;37(3):3123-3134.

10. Robens J, Goldstein L, Gown AM, et al. Thyroid transcription factor-1 expression in breast carcinomas. Am J Surg Pathol. 2010;34(12): 1881-1885.

11. Lin E, Li L, Guan Y, et al. Exon array profiling detects EML4-ALK fusion in breast, colorectal, and non-small cell lung cancers. Mol Cancer Res. 2009;7(9):1466-1476.

12. Niu FY, Wu YL. Personalized treatment strategies for non-small-cell lung cancer in Chinese patients: the role of crizotinib. Onco Targets Ther. 2015;8:999-1007.

13. Krytska K, Ryles HT, Sano R, et al. Crizotinib synergizes with chemotherapy in preclinical models of neuroblastoma. Clin Cancer Res. 2016;22(4):948-960.

14. Gambacorti Passerini C, Farina F, Stasia A, et al. Crizotinib in advanced, chemoresistant anaplastic lymphoma kinase-positive lymphoma patients. J Natl Cancer Inst. 2014;106(2):djt378.

15. Mosse YP, Lim MS, Voss SD, et al. Safety and activity of crizotinib for paediatric patients with refractory solid tumours or anaplastic large-cell lymphoma: a Children's Oncology Group phase 1 consortium study. Lancet Oncol. 2013;14(6):472-480.

16. Kazandjian D, Blumenthal GM, Chen HY, et al. FDA approval summary: crizotinib for the treatment of metastatic non-small cell lung cancer with anaplastic lymphoma kinase rearrangements. Oncologist. 2014; 19(10):e5-e11.

17. Costa DB, Shaw AT, Ou SH, et al. Clinical experience with crizotinib in patients with advanced ALK-rearranged non-small-cell lung cancer and brain metastases. J Clin Oncol. 2015;33(17):1881-1888. 
18. Yamaguchi N, Lucena-Araujo AR, Nakayama S, et al. Dual ALK and EGFR inhibition targets a mechanism of acquired resistance to the tyrosine kinase inhibitor crizotinib in ALK rearranged lung cancer. Lung Cancer. 2014;83(1):37-43.

19. Steuer CE, Ramalingam SS. ALK-positive non-small cell lung cancer: mechanisms of resistance and emerging treatment options. Cancer. 2014; 120(16):2392-2402.
20. Gadgeel SM, Gandhi L, Riely GJ, et al. Safety and activity of alectinib against systemic disease and brain metastases in patients with crizotinibresistant ALK-rearranged non-small-cell lung cancer (AF-002JG) results from the dose-finding portion of a phase $1 / 2$ study. Lancet Oncol. 2014;15(10):1119-1128.

\section{Publish your work in this journal}

OncoTargets and Therapy is an international, peer-reviewed, open access journal focusing on the pathological basis of all cancers, potential targets for therapy and treatment protocols employed to improve the management of cancer patients. The journal also focuses on the impact of management programs and new therapeutic agents and protocols on

\section{Dovepress}

patient perspectives such as quality of life, adherence and satisfaction. The manuscript management system is completely online and includes a very quick and fair peer-review system, which is all easy to use. Visit http://www.dovepress.com/testimonials.php to read real quotes from published authors.

Submit your manuscript here: http://www.dovepress.com/oncotargets-and-therapy-journal 